\title{
Blending Research And Teamwork To Enhance Undergraduate Education: Results From National Survey Of Student Engagement And Business ETS Major Field Test
}

Chris Ward, Ph.D., University of Findlay, USA

Dan Yates, Ph.D. University of Findlay, USA

Joon Young Song, Ph.D., University of Findlay, USA

\begin{abstract}
This study is a continuation of previous work by the authors. Most of the NSSE (National Survey of Student Engagement) scales are positively related to higher Business ETS MFT (Major Field Test) scores. The NSSE scales are Active and Collaborative Learning, Enriching Educational Experiences and Integration of Diversity into Coursework. In particular, the NSSE scale of Integration of Diversity into Coursework appears to be significant. Students seem to earn higher scores on the ETS MFT when diversity is integrated into courses. Two of the scales, however, are negatively related to GPA: Level of Academic Challenge and Integration of Diversity into Coursework. The items we added to the survey included a leadership position held on campus and, a NSSE item, the number of courses that expect students to put together ideas or concepts from different courses when completing assignments or during class discussions, were both significant. The positive partial correlation indicated a .223 and .181 (at the 5\% significance level), respectively, for these two items. Other items of interest will be discussed in the paper.
\end{abstract}

Keywords: NSSE; ETS MFT; Undergraduate Research; Student Engagement

\section{BACKGROUND}

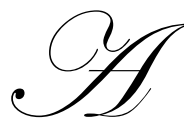

s students embark upon their life after college, it is important to consider the type of experience and learning provided in their college years. In the 2002 Greater Expectations report by AACU, universities are encouraged to move toward the intentional learner model. This model suggests students become three types of learners: empowered, informed and responsible. According to the report, the empowered learner includes the ability to communicate in diverse settings, employ a variety of problem solving skills and the ability to work well in diverse teams and build consensus. The informed learner includes areas of knowledge such as human imagination, global and cross cultural communities as well as the natural world. The responsible learner actively participates as a citizen in a diverse democracy and requires self-reflection.

The intentional learner model is beneficial to the student because it requires the student to become engaged in their education. While the student does have responsibility for a great deal of learning in this model, faculty members can become mentors by providing the types of experiences in classes that encourage and motivate students to be curious and require the student to integrate and synthesize content across courses. This intentional learner model is not new but it does reflect a shift in the type of practices considered valuable in undergraduate education. In the 1987 Chickering and Gamson's paper 'Seven Principles for Good Practice in Undergraduate Education', 
they recognized that "... undergraduate education should prepare students to understand and deal intelligently with modern life" (p. 3). Among other principles, the authors suggested contact between the students and faculty, developing a reciprocity and cooperation among students, and encouraging active learning gave way to a more meaningful undergraduate education. Many institutions are combining these three principles by having teams of students work with faculty on original research projects. Garde-Hansen \& Calvert (2007) supported this principle by stating "Such a taste of research-based learning is important in order that students develop a holistic sense of their curriculum and so that the increased focus on research-centered practice and self-directed study in later levels is well prepared for" (p. 108). In addition, "Allowing space in the curriculum for the emergence of a research community, even if that community is only evident for the briefest of moments, can certainly yield important results" (p. 108). For example, Munoz \& Huser (2008) described a project used in a Principles of Marketing class. Instead of focusing on the product mix, teams of students conduct a situational analysis. The project was organized into four sections (category analysis, competitive analysis, customer analysis and conclusions or new product idea). The work was distributed throughout the term to focus on the content and concepts relevant to each section of the project. In this example, experiential learning and cooperative learning are combined. Munoz and Huser (2008) state several benefits from this approach. First, embedding this project in a principles class "...should provide a stronger foundation of basic marketing or business concepts through improved communication" (p. 215) and group work “...allows for the development of interpersonal, leadership, and communication skills" (p. 215). The project also provides opportunities for students to develop skills necessary to be successful in business. These types of authentic assignments, that are similar to what a student may face once they get into the business world, “... can serve to assess multiple types of learning, and do so at sophisticated levels" (Association of American Colleges and Universities, 2002, p. 40). Munoz and Huser (2008) also found “ ... many students have never used online databases before and are content to simply Google search terms and use information from non-credible Web sites" (p. 217). This type of research project moves the student from a passive state to become more actively engaged in their learning (Munoz and Huser, 2008; Bonner, 2010) and they benefit from the relationship between teaching, learning and research (Garde-Hansen \& Calvert, 2007).

\section{RESULTS}

As a reminder, the four scales in NSSE are Level of Academic and Challenge, Active and Collaborative Learning, Enriching Educational Experiences and Integration of Diversity into Coursework. In addition, while the NSSE survey captures a great deal of the engagement items, we felt several additional questions or more insight into questions would assist us in our research. The questions added were the types of co-curricular activities students engaged in and the number of hours per week the student worked off campus. We also were able to get more specific data as we excluded the intercollegiate activities from the volunteer activities and asked if the student had held a position of leadership on campus (student government, resident assistant, club officer, etc.).

The specific partial correlations between the Business ETS MFT scores and the NSSE scale items are shown in Table 1 with OLS Regressions shown in Table 2. Three of the four scale items show a positive relationship to higher MFT scores.

Table 1: Partial Correlations between MFT and NSSE scale items

\begin{tabular}{|l|c|}
\hline \multicolumn{1}{|c|}{ NSSE scale items } & MFT \\
\hline Level of Academic and Challenge & -.074 \\
\hline Active and Collaborative Learning & .041 \\
\hline Enriching Educational Experiences & .134 \\
\hline Integration of Diversity into Coursework & $.183^{* *}$ \\
\hline
\end{tabular}

Table 2: OLS Regression between MFT and NSSE scale items

\begin{tabular}{|l|c|}
\hline \multicolumn{1}{|c|}{ NSSE scale items } & MFT \\
\hline I. Level of Academic and Challenge & -.423 \\
\hline II. Active and Collaborative Learning & .189 \\
\hline III. Enriching Educational Experiences & .400 \\
\hline IV. Integration of Diversity into Coursework & $.963 * *$ \\
\hline$*, * * * * *$ indicates significance at $10 \%, 5 \%$, and $1 \%$, respectively
\end{tabular}


The strongest relationship scale in both analyses is the Integration of Diversity into Coursework. The specific survey item, the number of courses in the last academic year that expected you to put together ideas or concepts from different courses when completing assignments or during class discussions, showed a significance level of 5\% for the partial correlation (.181) and OLS Regression (2.274).

The Enriching Educational Experiences scale item, which includes the survey question about holding a position of leadership on campus, was also significant. This particular item had a .223 positive relationship to MFT at the 5\% level of significance. This data is supported by the Association of American Colleges and Universities National Panel report 'Greater Expectations: A New Vision for Learning as a Nation Goes to College'. The report noted "... leadership skills can grow by theoretical study, leading a group in class, holding office in the student government, or being captain of a sports team" (p. 30). Close to 33\% of our students hold a position of leadership on campus with almost $68 \%$ are members of a club or group, another $3.6 \%$ are involved in a fraternity or sorority, and just over $2 \%$ are resident assistants. The results are not surprising and we found additional support in the literature at the Pascarella, et al (2010) study found the strongest linkage between Enriching Educational Experiences and the NSSE survey. They found a .44 partial correlation between the CAAP Critical Thinking Test and Enriching Educational Experiences and concluded by stating that engaging students in effective educational practices and experiences increases "the likelihood of improved institutional effectiveness and increased student learning and development" (p. 21). The Level of Academic Challenge did show a negative relationship to MFT and GPA. While not significant, this does indicate a potential learning curve for students that manifests itself in short term lower scores and grades but potentially longer term gains in actual transition from theory to practice. In addition, one plausible explanation for this is a survey question on this scale that asks the student to report the number of papers or projects of 20 pages or more during the academic year. Students may not consider the completion of business plans or other similar documents to be applicable when responding to this question. Another plausible explanation could be simply completing a paper or project of 20 or more pages may not be directly related to MFT or GPA, which measure business content knowledge. A better measurement might be a tool which measures written communication.

The survey questions did allow the students to report the number of courses in the academic year that required them to, or they participated in, Active and Collaborative Learning, Level of Academic Challenge, and Integration of Diversity into Coursework. As a frame of reference, students will be registered, on average, for 10 classes during an academic year. Over 58\% of the students reported that, during the academic year, their coursework emphasized applying theories or concepts to practical problems or to new situations; $83.2 \%$ of the students reported that three or more of their courses required them to work with other students on projects, $55.4 \%$ of the courses expected them to put together ideas or concepts from different courses when completing assignments or during class discussions; $43.1 \%$ said the coursework either most of the time or always emphasized synthesizing and organizing ideas, information, or experiences into new, more complex interpretations and relationships, and 77.3\% of the courses most of the time or always required them to integrate ideas or information from various sources.

This shift of integrating ideas across business functions is reflected in the results and is important in a student's development of critical thinking and problem solving skills. Bauer and Bennett (2003) reported that students who had participated in an undergraduate research program "reported greater enhancement of their ability to carry our research and a greater enhancement of the skills represented in the Communication and Personal Initiative factor" (p. 226). The differences, they noted “....appeared in the areas of independent achievement, (acquire information on my own, synthesize and use information from diverse sources, solve problems independently, better understand myself) and communication skills (listen effectively, write effectively, speak effectively)" (p.226). Providing students with the opportunities to conduct research, either directed or autonomous, combines all three types of learners in the intentional learner model and is obviously beneficial to the student.

Other important data gleaned from the analysis included OLS regression between the ETS MFT and GPA (grade point average) as well as comparisons between rank and gender. Table 3 reflects this data. Males score higher on the ETS MFT than females but females have a higher GPA. Seniors tend to score higher than juniors on the MFT. This is to be expected as the seniors have had additional opportunities to demonstrate knowledge through projects and other activities. Additional data found in Table 4 shows the regression coefficients of males and females on MFT and Table 5 shows the regression coefficients of males and females on GPA. With regard to MFT, 
three of the four NSSE scales are positive for male students while only two of the scales are positive for female students but almost the opposite is true for GPA. For females, two of the four NSSE scales are positively related to GPA while all four of the NSSE scales are negatively related to GPA for male students.

Table 3: OLS Regression

\begin{tabular}{|l|c|c|}
\hline \multicolumn{1}{|c|}{ Students personal data } & MFT & GPA \\
\hline Gender + & $-4.486^{*}$ & $.266^{* * *}$ \\
\hline Class ++ & 1.721 & $-.165^{* *}$ \\
\hline MFT & & $.014^{* * *}$ \\
\hline
\end{tabular}

$*, * *, * * *$ indicates significance at $10 \%, 5 \%$, and $1 \%$, respectively

${ }^{+}$Gender is coded as 1 and 2 for Male and Female, respectively.

${ }^{++}$Class is coded as 1,2, and 3for Sophomore, Junior, and Senior, respectively.

Table 4: Regression of MFT and NSSE scales (male and female students)

\begin{tabular}{|l|c|c|}
\hline \multicolumn{1}{|c|}{ NSSE Scale } & Males & Females \\
\hline I. Level of Academic Challenge & -.117 & -.011 \\
\hline II. Active and Collaborative Learning & .151 & -.116 \\
\hline III. Enriching Educational Experiences & .220 & .041 \\
\hline IV. Integration of Diversity into Coursework & .170 & .210 \\
\hline
\end{tabular}

Table 5: Regression of GPA and NSSE scales (Male and female students)

\begin{tabular}{|l|c|c|}
\hline \multicolumn{1}{|c|}{ NSSE Scale } & Males & Females \\
\hline I. Level of Academic Challenge & -.089 & -.018 \\
\hline II. Active and Collaborative Learning & -.002 & .068 \\
\hline III. Enriching Educational Experiences & -.022 & .051 \\
\hline IV. Integration of Diversity into Coursework & -.006 & -.269 \\
\hline
\end{tabular}

\section{CONCLUSION}

The overall results are encouraging. Internal changes in advising, such as recommending that juniors wait till their senior year to take the capstone course, appears to be having a positive impact on the results. In addition, while we have made some progress in closing the gap between females and males ( -5.629 to -4.486$)$ for ETS MFT scores since the previous reporting period, closing this gap completely may prove to be a long term issue and require further analysis of the data. In addition, further research should attempt to understand the differences between male and female students as they relate to ETS MFT/GPA and the NSSE scales.

Our focus on involving students in the community and providing students with an opportunity to put into practice the knowledge they have learned from other courses is supported in the literature. Garde-Hassen \& Calvert (2007) commented that by "...promoting undergraduate research through tying assessments to local community involvement may well be particularly enriching" (p. 114). In the Association of American Colleges and Universities National Panel Report, 'Greater Expectations: A New Vision for Learning as a Nation Goes to College', the authors suggested that campuses look beyond the classroom to issues the issues of society and the workplace. The report recommended that "... when studies reach beyond the classroom to the larger community, asking students to apply their developing analytical and ethical judgment to concrete problems in the world around them, and to connect theory with the insights gained from practice" (p.25-26) the students become active participants in the world around them. The students enhance their problem solving, teamwork and critical thinking skills in a way that pure lecture simply cannot do. This data serves as a reminder that our efforts are not wasted. It takes a collaborative effort by faculty to embrace this new model and to focus on student learning rather than teaching. 


\section{AUTHOR INFORMATION}

Dr. Chris Ward is an Associate Professor of Business at The University of Findlay. She brings her expertise from two Fortune 500 companies into the classroom teaching operations and logistics, marketing, leadership, and research courses. Professor Ward holds the following degrees: University of Sarasota, EdD, Organizational Leadership; The University of Findlay, MBA and Bachelor of Science in Business Administration. She is also a Six Sigma Black Belt, 2008 and 2010 Ohio Partnership for Excellence Examiner, and NxLevel Certified. Her areas of research include student engagement, active learning, undergraduate research, general education, small business marketing, and promotion and tenure. E-mail: cward@ findlay.edu. Corresponding author.

Dr. Dan Yates is an Associate Professor of Business at The University of Findlay. His teaching interests include entrepreneurship, leadership, organization development, and business strategy. Yates holds a $\mathrm{PhD}$ degree in Management from Northcentral University. He also has a MBA from University of Dayton, a Master of Organization Development degree from Bowling Green State University, and a BS in Accounting from Tiffin University. He completed the NxLevel Certification Course for Instructor Certification for teaching business plans at the Innovation Center (Ohio University). He has 30 years industrial and governmental experience. E-mail: yates@ findlay.edu

Dr. Song is an assistant professor of Finance at the University of Findlay. Prior to joining the University of Findlay, Dr. Song has worked for a nation-wide business newspaper and a researcher at the LG Economic Research Institute in Korea. Professor Song earned a doctoral degree in business administration with concentration of finance from University of Tennessee (Knoxville). He also holds several master degrees in business administration and economics from Seoul National University, Syracuse University, and the University of Tennessee. His current research interests are in the areas of Asset Pricing, Behavioral Finance, and Corporate Governance. E-mail: song@ findlay.edu

\section{REFERENCES}

1. American Council of Learned Societies. (April 2007). Student learning and faculty research: Connecting teaching and scholarship. A Teagle Foundation White Paper.

2. Association of American Colleges and Universities (2002). Greater Expectations: A new vision for learning as a nation goes to college. Washington, DC: Association of American Colleges and Universities.

3. Bauer, K., \& Bennett, J. S. (2003). Alumni perceptions used to assess undergraduate research experience. The Journal of Higher Education, 74 (2), 210-230.

4. Bonner, J. (2010). Taking a stand as a student-centered research university: Active and collaborative teaching meets the scholarship of teaching at the University of Alabama. JGE: The Journal of General Education. 95 (4), 183-192.

5. Brew, A. (April 2010). Imperatives and challenges in integrating teaching and research. Higher Education Research and Development, 29 (2), 139-150.

6. Chickering, A. W., \& Gamson, Z. M. (Fall 1987). Seven principles for good practice in undergraduate education. Washington Center News.

7. Dotterer, R.L. (Summer 2002). Student-faculty collaborations, undergraduate research, and collaboration as an administrative model. New Directions for Teaching and Learning, 90, 81-89.

8. $\quad$ Eagen Jr., M. J., Sharkness, J., Hurtado, S., Mosqueda, C.M., \& Chang, M. T. (2011). Engaging undergraduate in science research: Not just about faculty willingness. Research in Higher Education, 52, $151-177$

9. Garde-Hansen, J. \& Calvert, B. (2007). Developing a research culture in the undergraduate curriculum. Active Learning in Higher Education, 8 (2), 105-116.

10. Hu, S., Scheuch, K., \& Gayles, J. G. (2009). The influences of faculty on undergraduate student participation in research and creative activities. Innovation in Higher Education, 34, 173-183.

11. Lopatto, D. (Spring 2010). Undergraduate research as a high-impact student experience. Peer Review, Association of American Colleges and Universities, 27-30. 
12. Munoz, C., \& Huser, A. (March/April 2008). Experiential and cooperative learning: Using a situation analysis project in principles of marketing. Journal of Education for Business, 214-220.

13. O’Meara, K. \& Braskamp. L. (Winter 2005). Aligning faculty reward systems and development to promote faculty and student growth. NASPA Journal 42 (2), 223-240.

14. Pascarella, E.T, Seifert, T.A., \& Blaich, C. (January/February 2010). How effective are the NSSE Benchmarks in predicting important educational outcomes? Change, 16-22.

15. Reisburg, L. (1998). Research by undergraduate proliferates but is some just glorified homework? Chronicle of Higher Education, 44 (37), A45-A47. 